\section{LAS ORGANIZACIONES DE USUARIOS DE AGUA EN LA CONSTRUCCIÓN DE LA ESCASEZ HÍDRICA. DE LAS ACCIONES GEOLEGALES A UNA TERRITORIALIZACIÓN SECURITARIA DEL AGUA}

Chloé Nicolas Artero ${ }^{1}$

\section{Resumen}

En el contexto ideológico y jurídico hídrico chileno, orientado hacia la eficiencia del uso del agua, la existencia de huertos urbanos en el norte del país sorprende. El presente artículo analiza el rol de las organizaciones de usuarios del agua en la construcción de la escasez hídrica y de una territorialización hidrolegal securitaria de los huertos de Vicuña. Situado en un valle semiárido de Chile, el caso es representativo del manejo del agua por las organizaciones de regantes mediante una red de canales. Desde la geografía jurídica se analizan, utilizando metodologías cualitativas
THE WATER USER ORGANIZATIONS IN THE CONSTRUCTION OF WATER SCARCITY. FROM GEO-LEGAL ACTIONS TO A SECURITY TERRITORIALIZATION OF WATER

\author{
Chloé Nicolas Artero
}

\section{Abstract}

In the ideological and legal context of Chilean water, oriented towards the efficiency of water use, the existence of urban gardens in the north of the country is surprising. This article analyzes the role of water user organizations in the construction of water scarcity and a hydro-legal security territorialization in the urban gardens of Vicuña. Located in a semi-arid valley in Chile, the case is representative of canal water management and the intervention of irrigation organizations. From the legal geography, the relationships to law and space and the tensions that cross the boards of three water user 
(etnografía, entrevistas, observaciones, archivos), las relaciones al derecho y al espacio y las tensiones que atraviesan los directorios de tres organizaciones de usuarios del agua. Las relaciones de poder entre las organizaciones de usuarios del agua conducen a la definición de tres acciones geolegales (desmarque, alza de la cuota, ausencia de regularización) que producen la escasez hídrica en los huertos de Vicuña. Para hacer frente a ella, los dirigentes de la Comunidad de agua "Huertos de Vicuña" instrumentalizan el derecho de manera de aumentar su control sobre las prácticas de riego, lo que produce una territorialización securitaria del agua.

PALABRAS CLAVE: ORGANIZACIONES DE USUARIOS DEL AGUA; ESCASEZ HÍDRICA; TERRITORIALIZACIÓN HIDROLEGAL; HUERTOS URBANOS; CHILE

Recibido: 2019-12-19

Aceptado: 2020-05-19 organizations are analyzed. For this, qualitative methodologies are used (ethnography, interviews, observations, files). The power relations between water user organizations lead to the definition of three geo-legal actions (desmarque, increase in quota, absence of regularization) that produce water scarcity. To confront it, the leaders of the Community use the right to increase control over irrigation practices, leading to the formation of a secure territorialization of water.
Received: 2019-12-19

Accepted: 2020-05-19

1 Profesora Institut des Hautes Études de l'Amérique latine, Universite de la Sorbonne Nouvelle Paris III, Francia, https:// orcid.org/0000-0003-3879-3256. Correo electrónico: chloenicolasartero@gmail.com

\begin{abstract}
KEYWORDS: ORGANIZATIONS OF WATER USERS; WATER SCARCITY; HYDRO-LEGAL TERRITORIALIZATION; URBAN GARDENS; CHILE.
\end{abstract}




\section{Introducción}

El presente artículo se propone analizar y reflexionar sobre las relaciones de poder que se dan entre las organizaciones de usuarios del agua que producen la escasez hídrica y sobre sus reacciones frente a ella. La investigación se llevó a cabo en la ciudad de Vicuña ubicada en el valle de Elqui, al norte de la región de Coquimbo. Este caso es representativo de las regiones áridas o semiáridas, donde el agua es distribuida por organizaciones de usuarios a través de una red de canales. En Chile, estas organizaciones son compuestas por los titulares de derechos de agua. Mantienen cotidianamente las infraestructuras de riego (canales, compuertas) y reparten el agua conforme a las reglas que definen ellos mismos. Existen tres tipos de organizaciones cuyo nivel de responsabilidad en la cuenca difiere: las juntas de vigilancia, las asociaciones de canalistas y las comunidades de agua. Las primeras distribuyen el agua entre los usuarios de la cuenca, las segundas entre varios canales, y las ultimas entre los usuarios de un mismo canal. Existe una relación jerárquica entre estas organizaciones, siendo la junta de vigilancia la que tiene más poder en la definición de las reglas de distribución. En este artículo se analizan las relaciones de poder que se dan entre tres de estas organizaciones, con vistas a comprender la escasez hídrica en la ciudad de Vicuña, una de las últimas de Chile en poseer huertos urbanos. La Comunidad de agua Huertos de Vicuña los alimenta mediante cuatro acequias.

En el contexto ideológico y jurídico hídrico nacional, sorprende el uso del agua para los huertos urbanos. La constitución de 1980 y el Código de aguas de 1981 reconocen la propiedad privada sobre las aguas, lo que permite una reasignación de los títulos de derechos de agua por el mercado (Bauer, 2002, 2015). Según sus defensores, el precio del agua alentaría los usuarios a mejorar la eficiencia de su uso e induciría una asignación de los derechos de agua hacia los sectores más productivos que disponen de recursos económicos para adquirirlos. La reasignación por el mercado fomentaría el desarrollo económico del país puesto que apoya las empresas más dinámicas y generadoras de empleo (Vergara Blanco, 2014). En este contexto nacional, ¿cómo explicar la persistencia del uso de agua para huertos urbanos, cuya producción agrícola es, según este prisma ideológico, considerada como improductiva?

Las investigaciones que han abordado los problemas hídricos en Chile estos últimos años no han estudiado las organizaciones de usuarios del agua (Budds, 2012, 2013; Fragkou y McEvoy, 2016; Panez-Pinto, Faúndez-Vergara y Mansilla-Quiñones, 2017; Prieto, 2016, 2017 ; Romero Aravena, Romero-Toledo y Opazo, 2018). El artículo propone analizar las relaciones de poder entre las organizaciones de usuarios desde la geografía jurídica critica (Robinson y 
Graham, 2018); esta corriente interroga sobre las relaciones de los actores al derecho y al espacio que participan a la producción del espacio (Blomley, 1994), poniendo en evidencia los vínculos entre legalidad, espacialidad y poder (Braverman, Blomley, Delaney y Kedar, 2014; Forest, 2009a). Más aún; no solo los describe, sino que muestra como los actores movilizan de forma estratégica el derecho y el espacio para defender su posición política e intereses económicos.

La investigación utliza una metodología cualitativa orientada al estudio del derecho de aguas en acción desde una perspectiva geográfica (Melé, 2009). Se enfatiza la dimensión espacial de la cuestión normativa, alejándose así de una visión positivista del derecho y analizando sus actualizaciones locales. En el marco de un trabajo etnográfico en el valle de Elqui, la realización de entrevistas a diferentes categorías de actores permitió reconstituir las relaciones de poder entre organizaciones y la construcción social de la escasez hídrica en la ciudad. Para adoptar una perspectiva pluriescalar y diacrónica, se consultaron los archivos locales -de las organizaciones de usuarios de agua y los nacionales -de los Ministerios aferentes.

El artículo propone discutir la siguiente hipótesis: la escasez de agua de los huertos de Vicuña es producida por las relaciones de poder entre las organizaciones de usuarios que se manifiestan en la definición de acciones geolegales en torno a la distribución del agua. Frente a la escasez, la Comunidad de agua de Huertos de Vicuña toma una serie de decisiones que conducen a una territorialización securitaria del agua. En primer lugar, se presentará el estado del arte y la problemática del artículo, para en un segundo lugar describir la metodología de investigación. En tercer lugar, veremos como la transferencia de poderes de la municipalidad hacia las organizaciones de usuarios fue crucial en la construcción social de la escasez y en cuarto lugar se caracterizará el proceso de construcción de un territorio hidrolegal securitario, antes de presentar las conclusiones.

\section{Estado del arte y problemática}

En 2015, la Comunidad de agua "Huertos de Vicuña" no recibió agua durante cinco meses, lo que produjo efectos devastadores en la mayoría de los huertos urbanos. Al situarse en un valle semiárido, los distintos actores explican la escasez con razones climáticas, naturalizando y despolitizando el fenómeno (Bakker, 2000; Kaika, 2003). Aunque la variabilidad climática no puede ser negada (Salas, Jimenez y Montana, 2012), cabe señalar que existe un auge de la demanda de agua por los sectores extractivos como la minería o la agricultura de exportación (Nicolas-Artero, Velut y Aliste, 2018). Desde hace más de una década, estos grandes usuarios implementan 
tecnologías para evitar las pérdidas de agua por infiltración o evaporación, modernizando así las técnicas de recolección y distribución de agua (Alvarez, 2007). En este contexto, la existencia del riego por gravedad y los turnos de agua se convirtieron en un vestigio histórico.

El artículo analiza la escasez hídrica desde su construcción social y como un fenómeno que genera una reacción social por parte de los actores. La construcción social de la escasez ha sido estudiada desde su vertiente discursiva (Bakker, 2000; Heynen, Kaika y Swyngedouw, 2006) o material (Aguilera-Klink, PérezMoriana y Sánchez-García, 2000; Bossio et al., 2012), desde el punto de vista del estado y de sus diversos instrumentos de acción pública (Bourblanc y Blanchon, 2017; Mehta, Veldwisch y Franco, 2012) o desde el punto de vista de los actores privados transnacionales (Sosa y Zwarteveen, 2012). Sin embargo, ninguna investigación ha inquirido en el grado de escasez producida por las organizaciones de usuarios. En general, los autores adoptan una visión romantizada de éstas: las alteraciones de los sistemas hídricos administrados por los usuarios o por una comunidad suelen ser vistas como exógenas, producidas por la intervención del estado o del mercado (Boelens, 2011, 2016; Boelens, Getches y Guevara Gil, 2006; Boelens, Rocha y Guevara Gil, 2010). Las relaciones de poder dentro y entre éstas son invisibilizadas y su rol en la construcción de la escasez, negado. Desde la geografía jurídica, el artículo interrogará hasta qué grado las organizaciones de agua locales juegan un papel central en la producción de la escasez al definir las reglas de distribución del agua.

La escasez hídrica induce la implementación de respuestas políticas por los actores para enfrentarla. La noción de productividad social de la escasez ha sido utilizada para analizar dichas soluciones (Garcier, 2010; Kaika, 2003). Según Romain Garcier, "la escasez es un objeto de discurso que tiene una poderosa fuerza motriz y movilización política" (Garcier, 2010, p. 169). Esta noción proviene de la idea más amplia de productividad social de un conflicto, ampliamente discutida por politólogos, geógrafos y sociólogos (Aliste y Stamm, 2016; Damonte Valencia, 2015; Melé, 2012; Merlinsky, 2013; Ramírez, 2017). Por ejemplo, en Chile, se ha demostrado como los conflictos socio-territoriales a escala local, entorno a los glaciares o al agua, generan nuevas formas de politización de los habitantes y pueden llegar a transformar la agenda política nacional (Cortez y Maillet, 2018; Delamaza, Maillet y MartínezNeira, 2017). Nuestro trabajo contribuye a esta reflexión, centrándose, desde la geografía jurídica, en la dimensión jurídica y espacial de la productividad social de la escasez hídrica. A partir del caso chileno, analizamos cómo las reglas implementadas por las organizaciones de usuarios para hacer frente a la escasez, presentes en todo el continente, producen una territorialidad hídrica especifica. 
Para analizar la construcción social de la escasez y su productividad social desde la geografía jurídica, proponemos estudiar las acciones geolegales -definidas como la movilización conjunta y estratégica del derecho y del espacio que participa a la producción del espacio. En este sentido, la noción de acción geolegal se distingue, por su amplitud, de la noción de estrategia geolegal o de dispositivo geolegal. A diferencia de las estrategias geolegales, estas acciones no son necesariamente implementadas por un actor para defender sus intereses (Forest, 2009b). Tampoco se constituyen como instrumentos de acciones públicas definidos por el estado para controlar de forma no coercitiva a los sujetos, como es el caso de los dispositivos geolegales (Garcier, 2010). Por otra parte, ciertas decisiones y estrategias definidas por las organizaciones de usuarios para enfrentar la escasez establecen una organización y estructuración, material y/o ideal, de una porción de espacio (Girard y Rivière-Honegger, 2014). En ese sentido, pueden dar lugar a una territorialización del agua (Ghiotti, 2006), que califico como territorialización hidrolegal. A diferencia de la noción de territorio hidrosocial (Boelens, Hoogesteger, Swyngedouw, Vos y Wester, 2016; Ramírez, 2017), el análisis de su construcción se centra en las decisiones conjuntamente jurídicas y espaciales tomadas por los actores, cuyo objetivo es implementar una organización material e ideal específica para la distribución del agua. Cabe señalar que, a diferencia del territorio hidrosocial, esta territorialidad -siempre en proceso de construcción- no es necesariamente contestataria.

El artículo responde a las siguientes preguntas: ¿En qué medida las organizaciones de usuarios participan de la construcción social de la escasez? ¿Cómo esta escasez da lugar a una territorialización hidrolegal específica?

\section{Metodología}

La metodología apunta a estudiar las relaciones de poder que se desarrollan dentro y entre las organizaciones de usuarios para implementar acciones geolegales. El marco jurídico actual distingue tres tipos de organizaciones (Figura 1). En un primer nivel, están las comunidades de agua compuestas por los titulares de derechos que se reparten el agua a partir de un mismo canal. En un segundo, nivel se encuentran las asociaciones de canalistas, conformados por varias comunidades de agua que comparten una infraestructura común, como un canal o una bocatoma. En último lugar, las juntas de vigilancia se encargan de repartir el agua desde los ríos hasta las bocatomas de los canales, a escala de toda una cuenca o de parte de ella y, dentro de cada organización, un directorio define las reglas de distribución del agua. Entre las organizaciones mencionadas existe una relación de jerarquía y de poder, puesto que las juntas de vigilancia deciden de la cantidad de agua que reparten a las organizaciones en cada temporada. Además, 
cada titular de derechos de aguas superficiales pertenece de facto a una comunidad de agua y por ende, al resto de las organizaciones superiores; por esta pertenencia debe pagar una cuota mensual a cada organización.

El estudio de caso se realizó en la ciudad de Vicuña, capital de la comuna del mismo nombre (Figura 2). Construida en 1821, Vicuña es uno de los poblados más antiguos del valle de Elqui. Según el censo de 2017, la población de la ciudad se estimó en 11000 habitantes, frente a 27771 en la comuna. En 2013, el 25\% de la población se encontraba en una situación de pobreza económica y el número de hogares pobres excedía al promedio nacional. La mayoría de los habitantes son empleados del sector agropecuario. El centro de la ciudad se caracteriza por sus casas coloniales donde los patios internos albergan los huertos urbanos.

En su origen, respondían a una necesidad vital puesto que en ellos se cultivaban alimentos para el autoconsumo o el intercambio local. Debido a las subdivisiones de terrenos y a las construcciones de viviendas en el centro de la ciudad, la cantidad de huertos ha disminuido. Además, su función principal ha pasado a ser la de producir una amenidad ambiental y convertirse, de este modo, en un atractivo paisajístico para el sector turístico (Figura 3) (Sunkel, 2017); no obstante, muchos residentes mantienen su función alimenticia.

Los huertos son alimentados por cuatro acequias que atraviesan el centro de la ciudad y la implementación de turnos de agua. Desde los años 1990, la Comunidad de agua "Huertos de Vicuña" se encarga de ello con la ayuda de un turnero, a pesar de no estar formalizada legalmente como comunidad. Los huertos de la ciudad están rodeados por monocultivos de exportación, principalmente uvas. En el último tiempo la ciudad ha conocido una expansión urbana debido a la construcción de poblaciones, como es el caso en San IsidroCalingasta. Al mismo tiempo, el centro de la ciudad se densifica debido a la construcción de nuevas viviendas en algunos patios (Figura 4).

El presente artículo descansa sobre la implementación de diversos métodos de investigación cualitativos (observaciones, entrevistas, archivos). El principal trabajo fue el etnográfico, realizado en el valle de Elqui durante nueve meses -entre 2016 y 2018. Esa inmersión permitió escuchar conversaciones, observar las condiciones de vida locales y participar de las asambleas de las organizaciones estudiadas, anotando la información obtenida en cuadernos de campo. Además, la reflexión se basa en el análisis de los datos recopilados a partir de la realización de 40 entrevistas formales e informales a distintos actores (usuarios, organizaciones de usuarios, municipalidades, instituciones públicas regionales y nacionales) y a través de la consulta de archivos locales (organizaciones de usuarios, Conservador de Bienes Raíces) y nacionales (Ministerio de Obras Públicas). Todos estos datos fueron codificados usando el software ATLAS Ti para facilitar su análisis. 


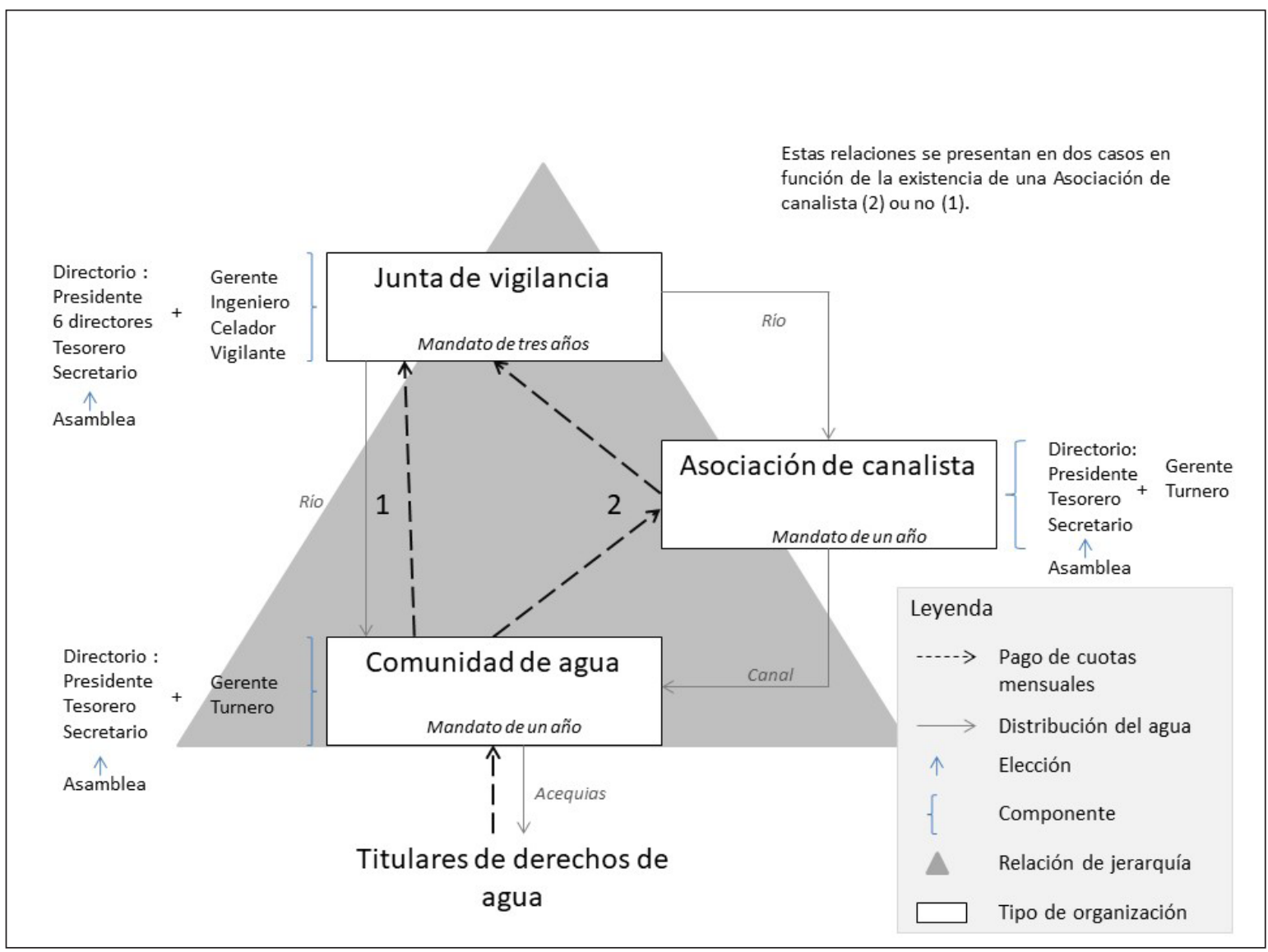

Fuente: elaboración propia. 
FIGURA 2. LA CIUDAD DE VICUÑA EN EL VALLE DE ELQUI.

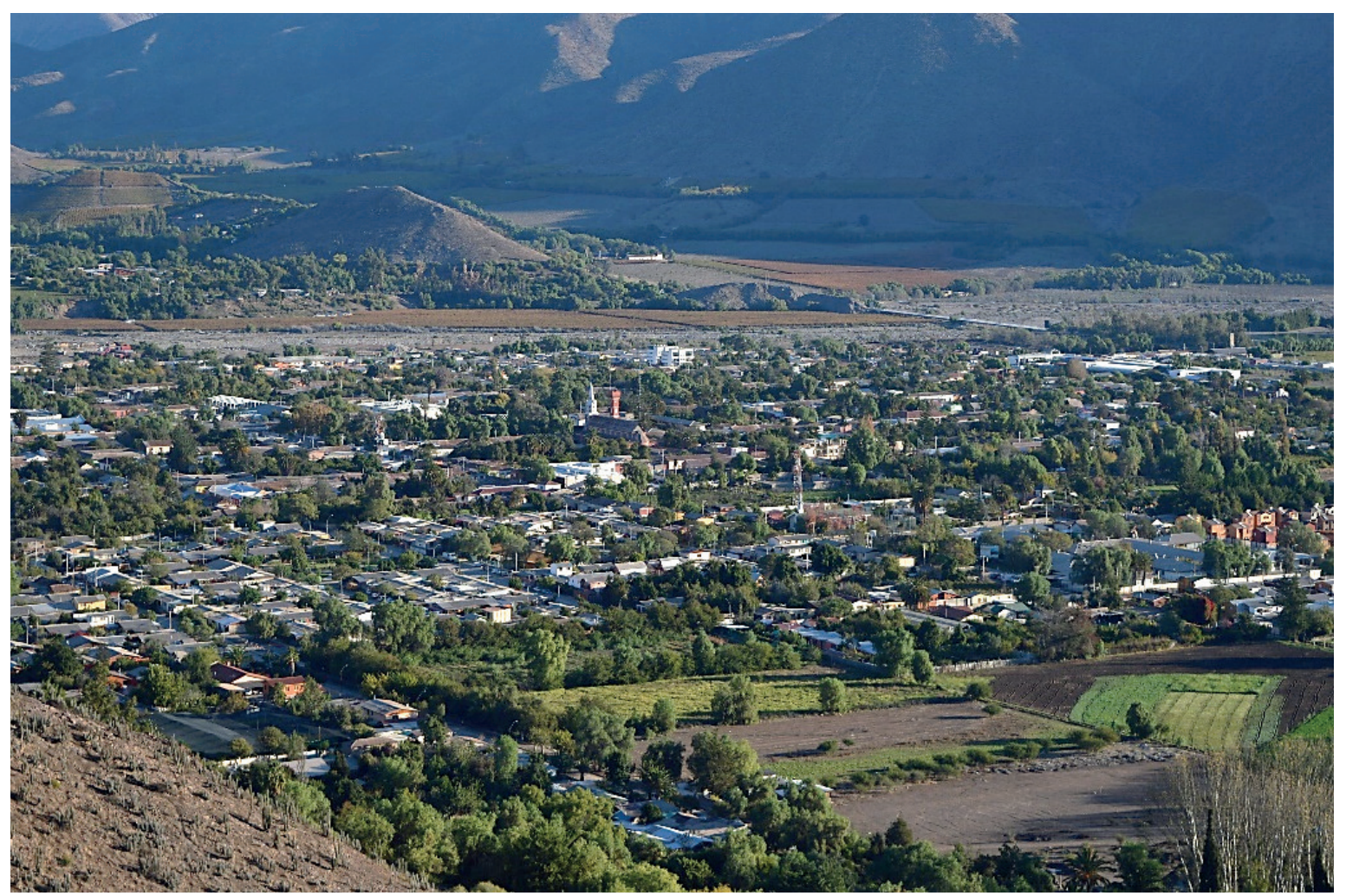

Fuente: elaboración propia. 
FIGURA 3. UN HUERTO URBANO EN UN HOSTAL DEL CENTRO DE LA CIUDAD.

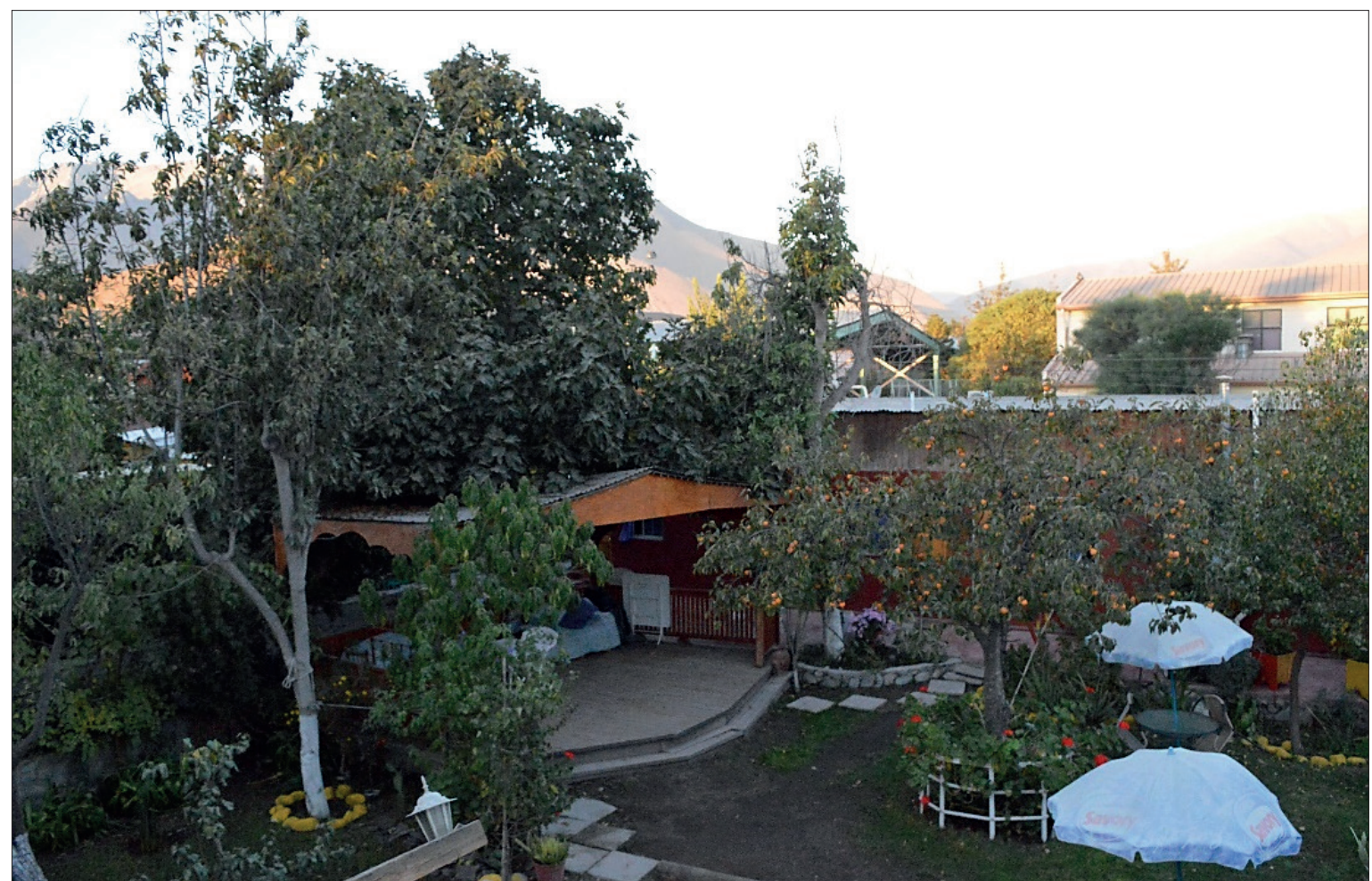

Fuente: elaboración propia. 
FIGURA 4. LA CIUDAD DE VICUÑA Y SUS ALREDEDORES EN LA PROVINCIA DE ELQUI.

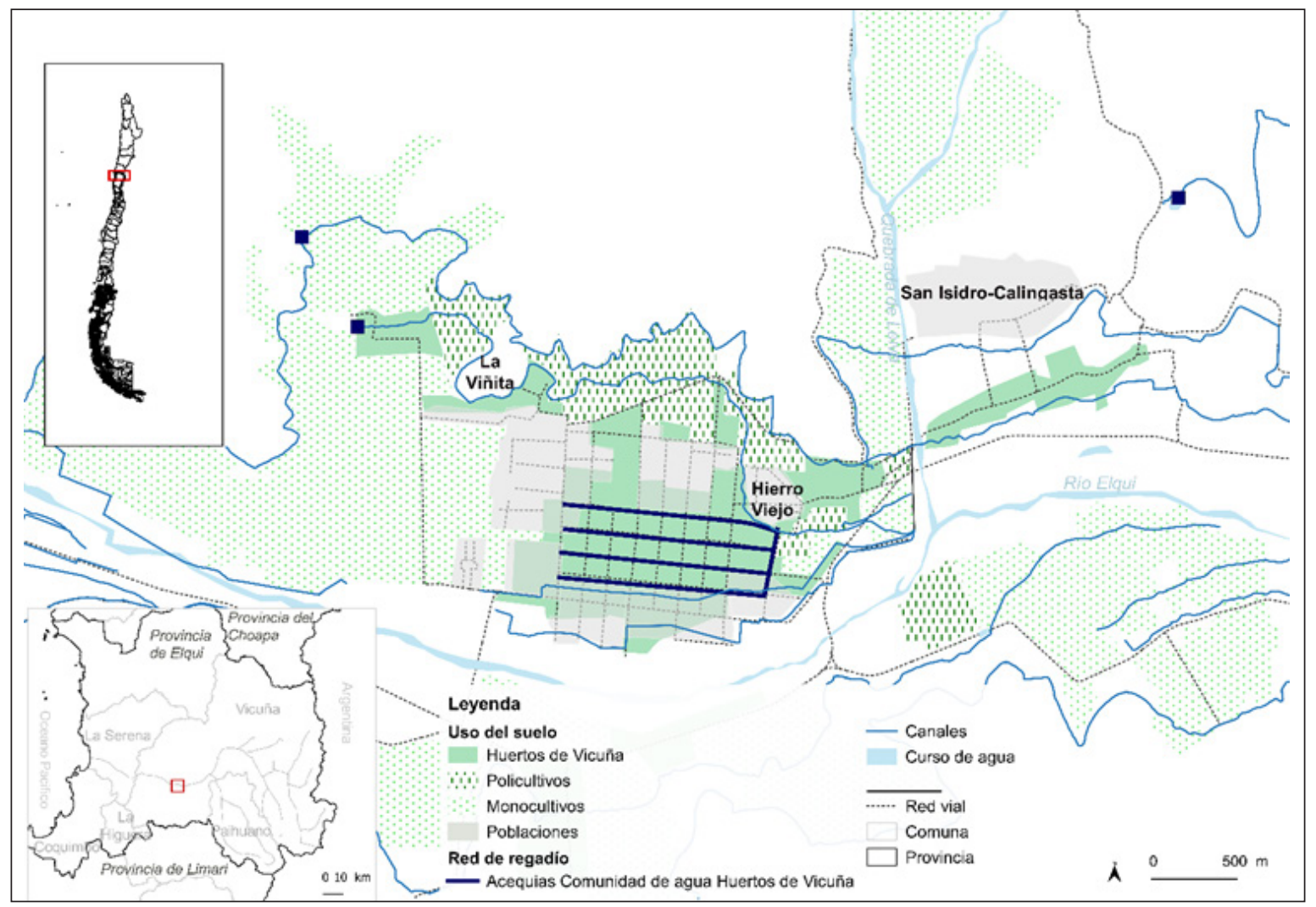

Fuente: elaboración propia con software Qgis. Datos: Programa PROMUS y BCN. SRC: EPSG:3857 - WGS 84. 


\section{La transferencia de poderes desde la municipalidad hacia las organizaciones de usuarios}

La escasez hídrica en los huertos de Vicuña se debe a una reconfiguración de las relaciones de poder entre las organizaciones de usuarios. Estos cambios explican la implementación de tres acciones geolegales - el alza de las cuotas mensuales a los usuarios, la aplicación del desmarque y el impedimento de regularización de la Comunidad de agua "Huertos de Vicuña" - que producen la escasez hídrica.

\section{UNA RECONFIGURACIÓN DE LAS RELACIONES ENTRE LAS ORGANIZACIONES DE USUARIOS}

Históricamente la municipalidad ha desempeñado un papel importante en la distribución de las aguas. Sus responsabilidades han disminuido en los últimos veinte años a favor de las organizaciones de usuarios circundantes. Antiguamente, el agua que circulaba por las acequias de la ciudad pertenecía a la municipalidad. Utilizaba parte de ella para humedecer los caminos de tierra y así reducir el polvo y el calor y la almacenaba en reservorios públicos ofreciendo acceso a los habitantes alejados de las acequias. Reconociendo este legado histórico, durante la regularización de los títulos de agua realizada por el Ministerio de Obras Públicas en 1995, éste otorgo a la municipalidad 76 acciones de agua. Tras esta regularización, la municipalidad concedió una parte de sus derechos a los usuarios de la ciudad. El presidente de la Comunidad de agua "Huertos de Vicuña" expone este fragmento de la historia local:

"En esos años la municipalidad era dueña de 76 acciones dentro de las cuales contemplaba el riego urbano. [...] Y como una forma de deshacerse de este problema de tener que administrar el agua para tantos usuarios, la municipalidad transfirió, en el año 1995, 43 acciones a lo que se denominó la "Comunidad de agua Huertos de Vicuña en formación", sin que esta comunidad tuviera existencia legal de acuerdo al Código de aguas."

Según el presidente, la municipalidad habría transferido parte de sus derechos para liberarse de una carga organizativa y económica. Sin embargo, esta transferencia coincide con los programas de regularización operados por el Ministerio de Obras Públicas (MOP) tras la construcción del embalse Puclaro. Por lo tanto, revela una obediencia de la municipalidad a los ingenieros que planificaron una nueva distribución del agua en la cuenca. El presidente de la Comunidad de agua "Huertos de Vicuña" revela la situación de subordinación del alcalde y de los usuarios hacia estos ingenieros: 
"La construcción del embalse conduce al MOP a regularizar los derechos de la cuenca, pero eee... lo hace muy mal porque dice: "mira nosotros identificamos este catastro de 252 casas con acceso al agua. Y de acuerdo con lo que tenemos de los registros de la municipalidad, a cada una le correspondería 0,01 acción". Más o menos, en promedio... No sé si eran 0,01, pero muchos usuarios con pequeños huertos usaban el agua y tenían derecho. ¡Y entonces crearon este engendro [la Comunidad] que tiene que organizarse y que parte sin financiamiento!"

Al traspasar 43 acciones de agua y la responsabilidad de establecer turnos de agua a la Comunidad de agua "Huertos de Vicuña", la municipalidad también respeta lo estipulado por el Código de aguas según el cual las organizaciones de usuarios deben administrar las aguas. Desde entonces, las funciones del Director de Obras Públicas de la municipalidad, en materia de administración de las aguas, son limitadas. La pequeña parte del agua que sigue teniendo la municipalidad -33 acciones en totales usada para el riego de los parques públicos. El traspase obligó a los usuarios de los huertos a administrar sus aguas a pesar de su falta de experiencia y de financiamiento. Por eso, en su discurso, el presidente describe este proceso como una obligación y compara la Comunidad de agua a un monstruo.

La transferencia de responsabilidades hacia las organizaciones de usuarios reconfigura las relaciones de poder entre ellas. Desde entonces, la Comunidad de agua "Huertos de Vicuña", compuesta por 252 usuarios, poseedoras de un total de 43 acciones, pertenece a la Asociación de Canalistas de "Villa o partera". Esta última dispone de 270 acciones, la mayoría pertenecientes a pequeñas comunidades de agua y a pequeños usuarios que son dueños de fracciones de acciones. Esto explica que la Comunidad de agua "Huertos de Vicuña", a pesar de sus 43 acciones, se convierta en el principal accionista de la Asociación de Canalistas "Villa o partera". De este modo, desde su creación, el directorio de la Comunidad de agua "Huertos de Vicuña" se encuentra en una posición de subordinación frente al de la Asociación de Canalistas y al de la Junta de vigilancia del Río Elqui (Figura 5). Cabe señalar que, en tanto titular de derechos de agua, la municipalidad se convierte en un usuario más de la Comunidad de agua Huertos de Vicuña y de la Asociación de Canalistas de "Villa o partera", pudiendo participar en las elecciones y en la toma de decisiones durante las asambleas. 
FIGURA 5. LA DIMENSIÓN ESPACIAL DE LAS RELACIONES JERÁRQUICAS ENTRE ORGANIZACIONES DE USUARIOS DEL AGUA EN VICUÑA. FUENTE: ELABORACIÓN PROPIA CON SOFTWARE QGIS.

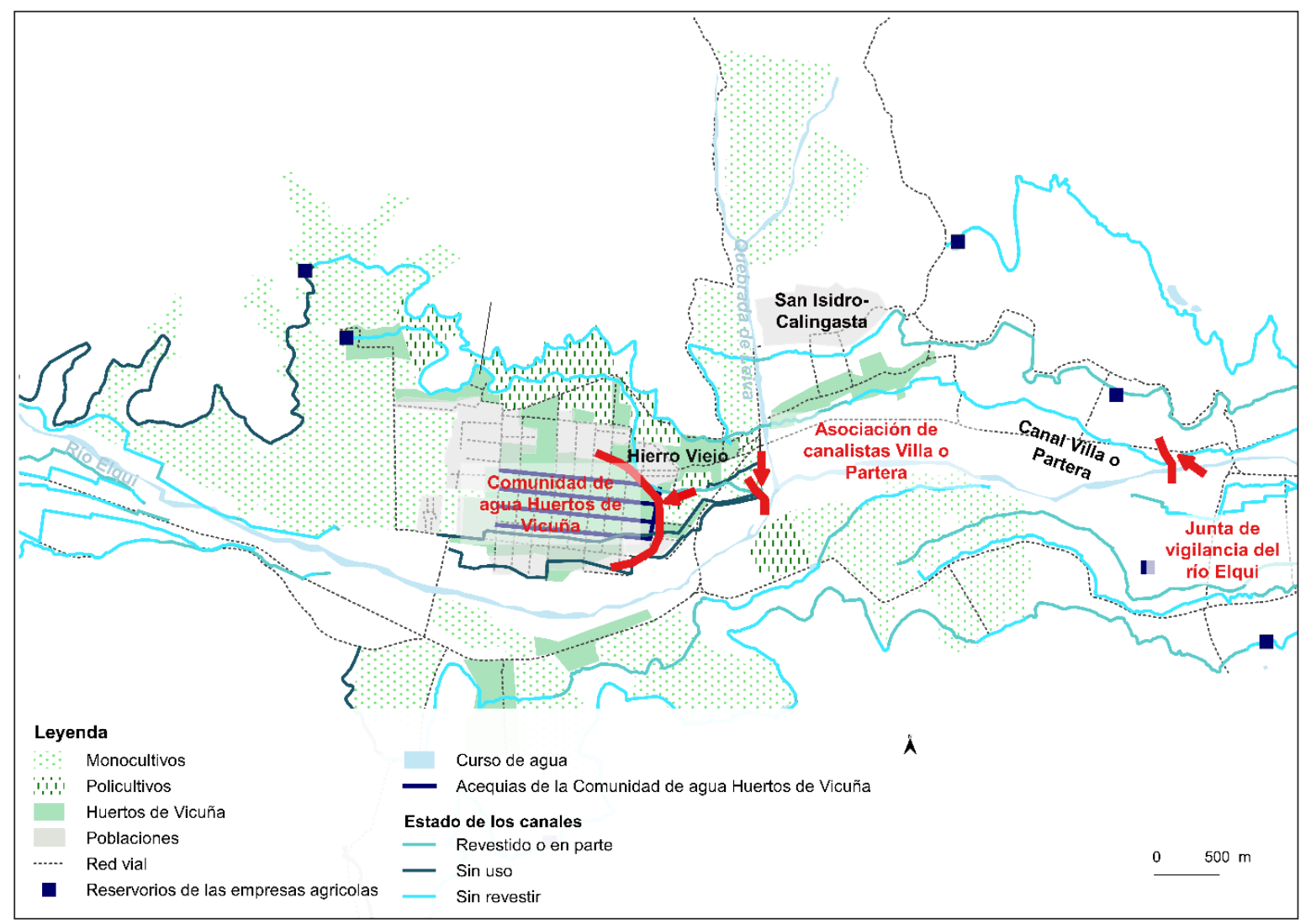

Fuente: Programa PROMUS y BCN SRC: EPSG:3857 - WGS 84. 


\section{LA APLICACIÓN DEL DESMAROUE Y EL ALZA DE LAS CUOTAS}

Dos acciones geolegales explican, en un principio, los cortes o la disminución del agua distribuida a los usuarios de los huertos urbanos: la aplicación del desmarque y el alza de las cuotas mensuales. Por una parte, según el Director de Obras Públicas de la municipalidad, la escasez constituye un problema histórico producido por la aridez de la región, el deterioro de las infraestructuras hídricas, y la aplicación del desmarque:

"Director: - Y existen problemas de abastecimiento. Ese es un problema histórico de acá de Vicuña. [...] Una acción de agua que significa? ¡En términos de flujo, es una tasa por segundo!

CNA: - Si claro. Por el desmarque...

D: - ¡Exacto! Entonces hoy el derecho de una acción de agua es de 250 centímetros cúbicos de agua por segundo. Pero en un riego primitivo, dónde los mecanismos de transporte son de tierra, ee... Esa agua no es suficiente para regar esta gran red ¡que es más grande que cualquier campo agrícola que tú puedas imaginar! Entonces la absorción del agua por la propia tierra, el mal uso que hacen algunos socios que pagan, y otros que no pagan, hacen que el proceso de traslado de las aguas hasta el final sea muy lento y difícil."
El desmarque representa un porcentaje de la distribución del agua que se aplica a cada acción de agua, calculado a partir del caudal promedio del río, definido en base a proyecciones del balance hídrico en cuatro años. Su aplicación reduce la cantidad de agua asociada a cada derecho y el caudal de los canales. Según el director, el desmarque explica parte de la situación de escasez. Sin embargo, para los usuarios, sería su causa principal. Durante una Asamblea de la Comunidad de agua "Huertos de Vicuña" observo el descontento de sus miembros tras el anuncio de una reducción del desmarque por el secretario:

El secretario anuncia, con un tono inquieto, una mala noticia. Durante el mes de junio y de julio, el agua distribuida por la Comunidad será de 5,9\%. "Entonces tendremos mucha menos agua durante esos meses", explica. La tensión sube. Una persona se exclama interrumpiéndole: "¿Y por qué? ¿Porque no tenemos agua? ¿Quién lo decide?" El secretario contesta con un tono a la vez firme y empático: "No lo sé, estoy en la misma situación que ustedes, pregúntenselo a la Asociación de Canalistas "Villa o partera"'. (Fragmento de cuaderno de campo, Vicuña, 2016).

El secretario se defiende de las críticas que le hacen los usuarios acusando a la Asociación de Canalistas "Villa o partera" de reducir el desmarque. En realidad, el directorio de la Junta de vigilancia del Río Elqui fue quien tomó la decisión de reducir su nivel de junio a julio para compensar un futuro aumento de septiembre 
a enero y así responder al alza de la demanda de los productores de uva de exportación. La disminución del desmarque perjudica a los usuarios que usan agua para regar sus huertos o sus policultivos de forma regular durante todo el año. Por lo tanto, la escasez de agua producida por la aplicación de la regla del desmarque responde a los intereses de las empresas agrícolas y se sustenta en la relación jerárquica que existe entre las organizaciones de usuarios. Esto revela cómo, al igual que el acaparamiento de tierras, "el acceso al agua no es simplemente una cuestión de volumen total, sino que está vinculada a la distribución en el tiempo y el espacio" (Mehta et al., 2012, p. 202).

Por otra parte, el corte de agua a los huertos urbanos, durante seis meses del año 2015, se explica por el endeudamiento de la Comunidad de agua "Huertos de Vicuña" con las organizaciones de agua superiores, como lo explica el Director de Obras Públicas:

"La gente de la ciudad que tiene acceso a estos derechos entiende que si no hay agua no tiene por qué pagar. Entonces se forma ahí un círculo vicioso. Dicen: “No hay agua, no pago!' O: "¡No me pidas que pague por algo que no tengo!" Entonces se generó ahí este atraso que hoy día existe. [...] Y a través de eso se generaban múltiples atrasos con la Asociación de Canalistas. Y esto, a su vez, producía que la Asociación durante el año pasado cortara el suministro durante 5 meses, lo que resultó casi fatal para los huertos de la ciudad. Esto fue de septiembre a enero, ¡esto fue terrible!"

Según el director, la frustración de los usuarios por no recibir agua suficiente explica el impago. Sin embargo, la deuda se generó pues la municipalidad traspasó sus derechos de agua a la Comunidad de agua «Huertos de Vicuña", como lo subraya su presidente:

"Autor:- ¿Tienen que pagar cuotas a la Asociación de Canalistas?

Presidente: - Así es.

A: - ¿Aunque no estén formados legalmente?

P: - Claro. Aunque no estemos formados legalmente estamos haciendo uso de un derecho. Eee... Podríamos no pagarlo, pero ellos podrían no darnos el agua. Estamos en una situación dónde se ha reconocido durante años el derecho de uso de estas aguas sin tener la propiedad durante todos esos años. Sin embargo, cuando se hace el traspaso de la administración, como yo te decía, se genera una situación de insolvencia de inmediato. Porque el costo del agua, con relación a las cuotas que se cobran y a los vecinos que no pagan sus cuotas, siempre generaba un déficit económico". 
El traslado de derechos de agua de la municipalidad hacia los usuarios generó la deuda de la Comunidad de agua "Huertos de Vicuña" con la Asociación de Canalistas "Villa o partera" y la Junta de vigilancia del Río Elqui. Más allá de la relación de subordinación, esta obligación se materializa por su dependencia a la red de canales formada en arborescencia (Figura 5). Si la Comunidad no paga sus cuotas, la Asociación tiene el poder de cortar el agua, tal como la Junta tiene ese poder sobre la Asociación. Los miembros de la Comunidad están obligados a pagar las cuotas a la Asociación y a la Junta, a pesar de su informalidad. Sin embargo, esta misma situación informal impide a su directorio ejercer una autoridad para recaudar las cuotas de los usuarios. Por lo tanto, la regularización de la Comunidad sería, según su directorio, la única solución para evitar el endeudamiento y, por ese medio, los cortes de agua.

\section{LOS OBSTÁCULOS A LA REGULARIZACIÓN DE LA COMUNIDAD}

Los miembros de la Comunidad de agua Huertos de Vicuña han conocido muchos obstáculos legales para regularizar su organización. Para llegar a ello, sus miembros deben probar ser dueños de los derechos de agua y de tierra, ya que anteriormente ambos estaban vinculados el uno al otro. El Tribunal de Letras de Vicuña reconoce legalmente a la Comunidad tan solo si todos los títulos son regularizados individualmente.
La lentitud y complejidad de este proceso, que identificamos como una tercera acción geolegal, explica la dificultad para formalizar la organización.

Ante estos obstáculos, el directorio propone formalizar la Comunidad, en un principio, a partir de un grupo de personas con los títulos ya regularizados. Sin embargo, esta estrategia fue rechazada por el juez para así no excluir de la organización a los usuarios que no hayan regularizado aún sus títulos. El directorio cuestiona esta decisión, pues el Código de aguas no impide que un individuo se una a la Comunidad tras su formalización. Finalmente, según el directorio, el rechazo de la solicitud provendría de un criterio personal del juez, razón por la cual prevé reiterar la estrategia tras su reemplazo.

Mientras tanto, esta irregularidad mantiene a la Comunidad de agua en una posición de subordinación frente a las decisiones tomadas por las organizaciones de usuarios superiores. La Comunidad tan solo tiene deberes hacia la Asociación de Canalistas y la Junta de Vigilancia; no derechos. Por ejemplo, no puede votar durante las asambleas de la Asociación. Si llega a formalizarse, la Comunidad se convertiría en el mayor accionista de la Asociación y obtendría una mayoría al unirse con la municipalidad. Esta alianza le permitiría tener más peso en la toma de decisiones, especialmente para definir el presupuesto anual, el nivel del desmarque o el de las cuotas. 
En resumen, sin negar totalmente la influencia de los factores climáticos y técnicos relacionados con la aridez y el estado de las infraestructuras, la escasez de agua en Vicuña es principalmente producida por tres acciones geolegales que conducen a la situación de endeudamiento, la aplicación de la regla del desmarque, y las dificultades que la Comunidad de agua Huertos de Vicuña enfrenta para regularizarse. Frente a esta escasez, el directorio de la Comunidad de agua toma una serie de decisiones internas que contribuyen a la construcción de un territorio hidrolegal securitario.

\section{Una territorialización del agua securitaria}

Para hacer frente a la escasez, los dirigentes de la Comunidad de agua "Huertos de Vicuña" instrumentalizan localmente el derecho, conduciendo a la construcción de un territorio hidrolegal securitario. Tras jugar con las reglas del proceso electoral para tomar el poder de la Asociación de $\mathrm{C}$ analistas, los dirigentes deciden aplicar una ordenanza municipal a los usuarios, amenazándoles con llamar a la policía e incautar sus bienes si no respetan los turnos de agua. Esta estrategia se acompaña de una disciplinarización de las prácticas de riego, con el objetivo de establecer un uso eficiente del agua.

\section{LAS DISPUTAS ELECTORALES}

Con el propósito de poner fin al corte de agua por endeudamiento, en un principio, un grupo de usuarios de la Comunidad de agua decide reembolsar una parte de la deuda. Este grupo está formado por empresarios turísticos o residentes recientemente establecidos en el centro de la ciudad, poseedores de un capital económico superior al promedio. Los huertos urbanos representan para ellos una amenidad medioambiental excepcional puesto que Vicuña sería la última ciudad en Chile en mantenerlos.

Su decisión de pagar la deuda revela no sólo una estrategia económica, sino también las ambiciones políticas de este grupo. Esta estrategia descansa sobre actualizaciones locales del derecho aferente al proceso electoral de las organizaciones de usuarios. El reembolso de parte de la deuda fue una promesa de campaña para ganar las elecciones y tomar el poder dentro de la Asociación de Canalistas, como lo afirma el presidente:

"CPresidente: - Y en esta asamblea que viene, gracias al acuerdo que se hizo judicialmente de reconocer esa deuda, y de proclamar una pausa en cuotas, se nos reconoció el derecho de voz y voto.

Autor: - ¿Para la que viene ahora en mayo?

P: - A partir de esa fecha.

A: - Que es el 29 o así... 
P: - A finales de mayo. Entonces en esa...

A: - Van a poder votar ustedes.

P: - Si. Y les vamos a sacar. Les vamos a sacar a todos.

A: -Y, ¿pero pueden ustedes sacarles?

P: - Como no va nadie, yendo 43 acciones más 33 de la municipalidad, y más algunos otros voto que tengo negociados por ahí...

A: - ¿Cuántos son en total en la asociación?

P: - 270 acciones. (Tose) Como normalmente no va nadie y nosotros somos los más grandes de lejos con la municipalidad y algunos otros particulares. ¡Vamos a tener mayoría en la segunda citación y ahí los vamos a sacar a todos!"

Apenas un grupo de personas reembolsó la deuda de la Comunidad de agua, la Asociación "villa o partera" le reconoció el derecho a voto en las elecciones. El presidente de la Comunidad quiere ganarla estas elecciones para remplazar al directorio de la Asociación de Canalistas. Este acuerdo entre las dos organizaciones muestra la existencia de negociaciones y tratos dentro y entre las organizaciones de usuarios de agua para que algunos usuarios obtengan el poder de dictar las reglas de distribución del agua. En muchos sentidos, estas organizaciones funcionan como partidos políticos y desarrollan estrategias clásicas de toma de poder (Bourdieu, 2001).

Sin embargo, durante el proceso electoral los miembros del directorio de la Comunidad de agua "Huertos de Vicuña" no lograron ser elegidos en calidad de directores de la Asociación de Canalistas. Después de llegar a un acuerdo con la municipalidad para contar con su apoyo, el representante de ésta no participó en las elecciones. La presencia de la municipalidad era fundamental para ganar ya que es la segunda accionista después de la Comunidad. Sumando sus derechos, el directorio podía obtener la mayoría de los votos. Este fracaso destaca la importancia estratégica de las negociaciones políticas que se dan al margen de las asambleas y las cooptaciones existentes entre usuarios. A pesar de eso, de todas maneras, durante las elecciones, el voto se realizó a mano alzada sin aplicar los prorrateos en función de la cantidad de derechos de agua pertenecientes a cada usuario. Esta forma de operar revela cómo, según las relaciones de poder locales, la regla del sufragio censitario proporcional al número de derechos de agua establecido por el ódigo de aguas no se aplica sistemáticamente. 


\section{VIGILAR Y AMENAZAR}

Después de su fracaso electoral, para evitar pérdidas y malgastos, el directorio de la Comunidad de agua "Huertos de Vicuña" opta por amenazar con el uso del poder policial para así aumentar su control sobre el reparto de las aguas. Para ello, el presidente de la Comunidad incauta una ordenanza municipal promulgada en 1985 que nunca había sido aplicada por la municipalidad. De esta forma, los dirigentes recurren a un texto jurídico local para legitimar la aplicación de nuevas reglas de distribución. Esta estrategia trata de evitar un nuevo corte de agua por endeudamiento y la situación de escasez.

La ordenanza obliga los habitantes a mantener las acequias en buen estado y respetar los turnos de agua. Con ella, la Comunidad obtiene la posibilidad de castigar a aquellos que no la respetan denunciándolos a la policía. Así podría, a modo de sanción, confiscar los bienes inmuebles de los habitantes. El amparo dado por esta ordenanza municipal revela el traspaso de un poder potencial, tradicionalmente asumido por las autoridades públicas al directorio de una Comunidad de agua informal. Este fenómeno se inscribe en la reducción de la responsabilidad estatal en la gestión de los recursos hídricos y revela una reconfiguración de las atribuciones legales locales entre el Estado y las organizaciones de usuarios.
FIGURA 6. ORDENANZA MUNICIPAL PARA EL USO Y DISTRIBUCIÓN DE LAS AGUAS DEL SISTEMA DE REGADÍO URBANO.

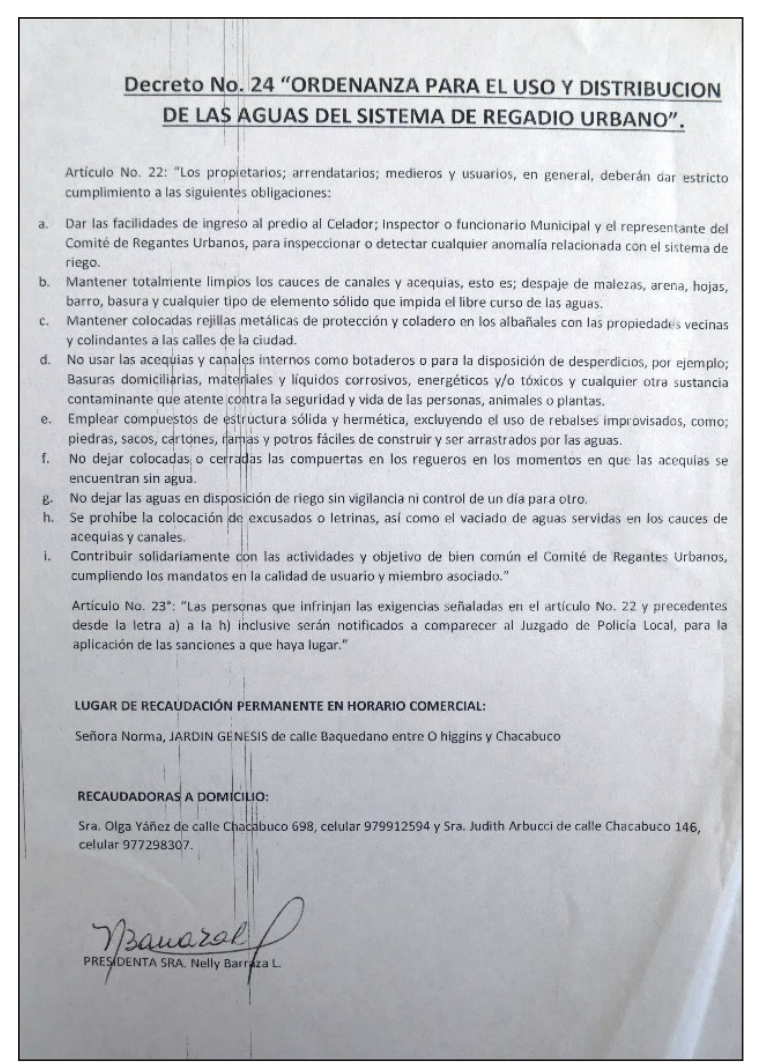

Fuente: elaboración propia. 
El fortalecimiento del control sobre los turnos de agua tiene repercusiones sobre el comportamiento de los usuarios. Conversando con un habitante acerca de la escasez hídrica y la posibilidad de tomar agua de la acequia ilegalmente, este demuestra temor ante la posible intervención de la policía:

Me explica que existen problemas con el agua porque ahora está separada de la tierra. La casa del vecino perdió todos sus árboles porque el antiguo dueño había vendido la tierra y los derechos de agua por separado, de modo que el dueño actual no tenía acceso al agua. Le pregunto cómo se las arreglaba, si acaso no podía usarla igualmente. Se ríe avergonzado, y después me contesta con un tono serio: "el problema es que ahora si te ven haciendo eso, pueden venir los carabineros y puedes tener problemas con la justicia". (Fragmento de cuaderno de campo, Vicuña, 2017).

Este testimonio revela como la amenaza presentada por el directorio de la Comunidad modifica el comportamiento de los usuarios. Genera miedo y tiende a conducirles a respetar los turnos de agua, tomando únicamente el agua correspondiente.

El fortalecimiento del control sobre las aguas se basa en una estigmatización de prácticas de riego, consideradas ineficientes, como la obstrucción de canales y el incumplimiento de los turnos de agua. Existe un juzgamiento peyorativo sobre el riego de los huertos urbanos, como lo revela el Director de Obras Públicas de la municipalidad:

"Director: - Tenemos que velar a que el agua pase, que trascurra de manera que no se desperdicie. Ha costado mucho porque nuestro trabajo es velar permanentemente contra los... a ver, en contra de las malas costumbres de los usuarios, que echan basura, que... ¿Qué se yo?... Y tú has visto que de repente corre el agua por las calles, porque de repente pasa por los huertos y la gente no cuida. Hay un conflicto entre el uso urbano del agua y el uso agrícola. ¿Ya? En el campo la gente cuida el agua, yo creo que tiene mediano sentido de cuidar el agua, pero en la ciudad no. [...] El canal de repente pasa por una población, en dónde a la gente le importa poco el canal. Le importa poco todo lo que es el aprovechamiento del agua, porque no lo necesitan, les da lo mismo. Y lo transforman en vertedero."

Según el director de Obras Públicas, los habitantes de las ciudades no cuidarían el agua de manera adecuada, a diferencia de los habitantes rurales. Este discurso muestra además una simplificación y generalización de las relaciones de los habitantes de las poblaciones al agua de las acequias. Al no usar el agua, percibirían las acequias como alcantarillas. Los directorios de 
las organizaciones toman el ejemplo de la mala gestión de los residuos por parte de algunos habitantes para acusar a los usuarios del centro de la ciudad de desarrollar malas prácticas de riego. Sin embargo, no todos los usuarios tiran sus residuos en las acequias. Si tal fuera el caso, los habitantes no se enojarían ni se organizarían para defender los huertos de Vicuña. Más que un mal comportamiento, la obstrucción de las acequias se debe a una modificación de los usos del agua producida por la transformación del metabolismo urbano (Swyngedouw, 2004). La urbanización de la ciudad, su densificación, y la reducción de la cantidad y del tamaño de los huertos, conduce a una desaparición paulatina del uso de las acequias para regarlos. En este contexto, la amenaza de llamar a la policía se asemeja a una respuesta inadaptada a la producción urbana inducida por procesos económicos más complejos (Figura 4).

\section{DISCIPLINAR LAS PRÁCTICAS DE RIEGO}

Al fin, los dirigentes de la Comunidad de agua "Huertos de Vicuña" optan por modificar las prácticas y valorar nuevas tecnologías de riego (Li, 2008; Moore, 2006; Peluso y Lund, 2011). Este giro se asemeja a una disciplinarización de las prácticas de riego, en el sentido que Michel Foucault otorga al de disciplina (Foucault, 1976). Según él, el poder disciplinario busca producir cuerpos "dóciles y útiles" forjando así la gubernabilidad de los individuos, dónde el poder no solo se concretiza mediante la aplicación de la ley y una sanción, sino por una serie de dispositivos que orientan la racionalidad y así el comportamiento de los individuos. Esta disciplinarización constituye para el directorio una manera de regir el comportamiento de los usuarios sin decretar explícitamente reglas formales.

El discurso del secretario de la Comunidad durante una asamblea ilustra la voluntad de disciplinar los cuerpos en las prácticas de riego:

La persona responsable de la distribución del agua explica que, según él, los habitantes tienen que ser más eficientes: "Tenemos que ser lo más eficiente posible con lo que existe, ya que, como lo he indicado antes, es lo que hay". Después de eso, menciona todos los problemas vinculados al riego en la ciudad: las rejas están sucias, las personas que se encuentran al final del canal no tienen acceso al agua, existe una falta de mantenimiento. "Tal como ustedes pagan la electricidad, tienen que pagar la televisión, el agua potable, iy tienen que preservar el agua!" Pide que se deje la compuerta abierta para que los demás puedan regar: "¡No podemos regar solos!". Según él, falta solidaridad entre los vecinos. "Se pierde mucha agua porque las personas riegan mal. ¡Todos nosotros!" Se incluye. Solicita a las personas que sean más cuidadosas. Si a veces no usan el agua, les pide que la dejen fluir y pasar, y que, por solidaridad, no cierren la compuerta. Explica que: "Todo no puede ser resuelto por el directorio o el gobierno. ¡Tenemos también que encargarnos nosotros mismos!" Subraya que los sábados y los 
domingos el turnero no trabaja. Invita a las personas a regar sus tierras y a organizarse para aprovechar toda el agua. (Fragmento del cuaderno de campo, Vicuña, 2016).

Durante la asamblea, el directorio presenta lo que define como buenas prácticas de riego: ser limpio y solidario para no romper los turnos de agua. El objetivo es ser lo más eficiente posible, es decir, reducir el desperdicio y ahorrar agua, mientras se pide a los usuarios pagar por el agua, tal como pagan por la luz o la televisión. Este pensamiento revela una concepción mercantil del agua. El directorio también subraya la importancia de la autogestión entre los miembros, lo que indica que, según él, el problema de la escasez es responsabilidad de los usuarios y no proviene del accionar del directorio o del Estado.

Este discurso busca generar en los usuarios un sentimiento de resignación frente a la baja cantidad de agua que recibe la Comunidad. Induce una naturalización y una despolitización de la escasez hídrica. Explicando esta última por el desperdicio del agua debido a las malas prácticas individuales, lo que justificaría la implementación de un mayor orden y disciplina, especialmente en los turnos de agua. El directorio convoca la responsabilidad individual para resolver problemas que surgen de la producción urbana. Solicita a los usuarios que cambien sus prácticas agrícolas: usar menos agua y reducir las plantaciones, lo que conduciría a la desaparición gradual de los huertos. Esta solicitud de índole moralizante apunta a que los usuarios se sientan responsables y culpables de la escasez. Sin embargo, en ningún momento se cuestiona el uso masivo de agua por parte de las empresas agrícolas situadas en los alrededores de la ciudad.

La negación del origen social de la escasez consolida la creencia en sus causas naturales (Linton y Budds, 2014). Esta naturalización hace pensar que se puede resolver un problema social solo con respuestas técnicas (Linton, 2010). Es la razón por la cual el directorio decide invertir en nuevas tecnologías de riego y comienza a usar los términos y objetivos de los gerentes de las empresas agrícolas. Por ejemplo, quiere implementar el recubrimiento de los canales con geomembrana e instalar un reservorio para acumular el agua por la noche. Estas soluciones actuarían como dispositivos técnicos que modificarían las prácticas de riego de los usuarios, convirtiéndolas en más eficientes y útiles. De este modo, los dirigentes asumen una concepción del agua «moderna» (Linton, 2010). En ese sentido, el presidente de la Comunidad de agua "Huertos de Vicuña" considera el riego por surcos en la ciudad como obsoleto:

"En un riego primitivo donde los mecanismos de transporte son de barro el agua es insuficiente para regar los huertos." (Fragmento del cuaderno de campo, Vicuña, 2016). 
El uso del adjetivo "primitivo" revela una desvalorización de las antiguas técnicas de riego que los habitantes usaban antes de la inserción de tecnologías en el valle. Es un juicio que refiere a un imaginario semántico con connotaciones coloniales.

\section{Conclusión}

En el contexto jurídico del derecho de aguas chileno, orientado a mejorar la eficiencia del uso del agua, la alimentación en agua de huertos urbanos es sorprendente. El estudio de caso de la ciudad de Vicuña muestra como, en realidad, están amenazados por cortes de agua y por una desvalorización de las prácticas de riego por surcos y por turnos. La investigación cualitativa, focalizada en el estudio del derecho de aguas en acción desde una perspectiva geográfica, ha revelado el rol que tienen las relaciones de poder entre organizaciones de usuarios del agua en la construcción social de la escasez hídrica y en la búsqueda de una mayor eficiencia en el uso del agua por sus miembros. Ausentes en las investigaciones sobre Chile, estas organizaciones han sido muchas veces idealizadas en la literatura latinoamericana, una mirada que este trabajo viene a cuestionar.

El artículo contribuye a la discusión científica sobre la escasez hídrica, en su construcción y su productividad social, al enfatizar la dimensión espacial del derecho de aguas.
Desde la geografía jurídica crítica, el principal aporte teórico es mostrar cómo el análisis de la apropiación del derecho y del espacio es indispensable para entender el rol de las organizaciones de los usuarios del agua en la construcción de la escasez hídrica y su reacción frente a ella. Para ello, se proponen las nociones de acciones geolegales y de territorialización hidrolegal.

Por una parte, se ha mostrado como las relaciones de poder entre las organizaciones de usuarios producen la escasez hídrica a través de la implementación de tres acciones geolegales: la aplicación del desmarque, el alza de las cuotas de agua y la dificultad de regularizar la Comunidad de agua. El conjunto de estas acciones explica el corte de agua a los usuarios de los huertos urbanos y la reducción de su caudal.

Por otra parte, se ha ilustrado cómo la productividad social de la escasez puede conducir a una territorialización securitaria del agua. Hemos revelado la instrumentalización local del derecho de aguas que realiza el directorio de la Comunidad de agua "Huertos de Vicuña" para evitar la situación de escasez. Tras usar estratégicamente las reglas que definen el proceso electoral de las organizaciones, los dirigentes se amparan en una ordenanza municipal para aumentar el control sobre las aguas, de la mano de una disciplinarización de las prácticas de riego. Todas estas decisiones producen una territorialización hidrolegal 
securitaria del agua, caracterizada por una organización y estructuración, material y/o ideal, especifíca de la gestión del agua del centro de la ciudad. En efecto, los dirigentes tratan de mejorar la eficiencia del uso y la eficacia de la gestión del agua, considerada como un bien naturalmente escaso. Esto pasa por aumentar el control sobre las prácticas de riego, la valorización de nuevas tecnologías y la determinación de buenas y malas prácticas de riego.

\section{Agradecimientos}

Investigación de doctorado realizada en el Centre de Recherche et de Documentation des Amériques, financiada por la Université Sorbonne-Nouvelle Paris III entre 2015 y 2019.

\section{Referencias bibliográficas}

Aguilera-Klink, F., Pérez-Moriana, E., y SánchezGarcía, J. (2000). The social construction of scarcity. The case of water in Tenerife (Canary Islands). Ecological Economics, 34(2), 233-245.

https://doi.org/10.1016/S0921-8009(00)00160-9

Aliste, E. y Stamm, C. (2016). Hacia una geografía de los conflictos socioambientales en Santiago de Chile: lecturas para una ecología política del territorio. Revista de Estudios Sociales, (55), 4562. https://doi.org/10.7440/res55.2016.03
Alvarez, P. (2007). Un itinéraire de l'eau, approche géographique et agronomique d'une gestion de lirrigation en zone aride du Chili. (Tesis de doctorado, Universidad de Lille, Francia)

Bakker, K. J. (2000). Privatizing water, producing scarcity: The Yorkshire drought of 1995. Economic geography, 76(1), 4-27. https://doi.org/10.1111/j.1944-8287.2000.tb00131.x

Bauer, C. J. (2002). Contra la corriente: privatización, mercados de agua y el Estado en Chile. Santiago de Chile: LOM.

Bauer, C. J. (2015). Canto de sirenas: El derecho de aguas chileno como modelo para reformas internacionales. Santiago de Chile: Ediciones El Desconcierto.

Blomley, N. (1994). Law, space, and the geographies of power. Guilford Press.

Boelens, R. (2011). Luchas y defensas escondidas. Pluralismo legal y cultural como una práctica de resistencia creativa en la gestión local del agua en los Andes. Anuario de Estudios Americanos, 68(2).

https://doi.org/10.3989/aeamer.2011.v68.i2.554

Boelens, R. (2016). Water, power and identity: The cultural politics of water in the Andes. London: Routledge

Boelens, R., Getches, D. H., y Guevara Gil, J. (Eds.). (2006). Agua y derecho: políticas hídricas, derechos consuetudinarios e identidades locales. Lima: IEP Instituto de Estudios Peruanos.

Boelens, R., Hoogesteger, J., Swyngedouw, E., Vos, J., y Wester, P. (2016). Hydrosocial territories: 
A political ecology perspective. Water International, 41(1), 1-14.

https://doi.org/10.1080/02508060.2016.1134898

Boelens, R., Rocha, R., y Guevara Gil, J. A. (2010). Lo colectivo y el agua: Entre los derechos y las prácticas. Lima: Instituto de Estudios Peruanos.

Bossio, D., Erkossa, T., Dile, Y., McCartney, M., Killiches, F., y Hoff, H. (2012). Water implications of foreign direct investment in Ethiopia's agricultural sector. Water alternatives, 5(2), 223-242. Recuperado de http://www.water-alternatives.org/index.php/ alldoc/articles/vol5/v5issue2/167-a5-2-3

Bourblanc, M. y Blanchon, D. (2017). Gérer ou gouverner la ressource en eau? Modélisation en temps réel et gestion de la pénurie au sein de la rivière Crocodile (Afrique du Sud). Natures Sciences Sociétés, 25(2), 134-147. https://doi.org/10.1051/nss/2017022

Bourdieu, P. (2001). Langage et pouvoir symbolique. Paris: Éditions du Seuil.

Braverman, I., Blomley, N. K., Delaney, D., y Kedar, A. (Eds.). (2014). The expanding spaces of law: A timely legal geography. Stanford: Stanford University Press.

Budds, J. (2012). La demanda, evaluación y asignación del agua en el contexto de escasez: un análisis del ciclo hidrosocial del valle del río La Ligua, Chile. Revista de Geografía Norte Grande, (52), 16784

https://doi.org/10.4067/S0718-34022012000200010
Budds, J. (2013). Water, power, and the production of neoliberalism in Chile, 1973-2005. Environment and Planning D: Society and Space, 31(2), 30118.

https://doi.org/10.1068/d9511

Cortez, M. y Maillet, A. (2018). Trayectoria multinivel de una coalición promotora e incidencia en la agenda política nacional. El caso del conflicto de Pascua Lama y la ley de glaciares en Chile. Colombia Internacional, (94), 3-25.

https://doi.org/10.7440/colombiaint94.2018.01

Damonte Valencia, G. H. (2015). Redefiniendo territorios hidrosociales: control hídrico en el valle de Ica, Perú (1993-2013). Cuadernos de Desarrollo Rural, 12(76), 109-133.

https://doi.org/10.11144/Javeriana.cdr12-76.rthe

Delamaza, G., Maillet, A., y Martínez-Neira, C. (2017). Socio-territorial conflicts in Chile: Configuration and politicization (20052014). European Review of Latin American and Caribbean Studies, 104, 23-46.

https://doi.org/10.18352/erlacs.10173

Forest, P. (Dir.). (2009a). Géographie du droit épistémologie, développement et perspectives. Québec: Presse Universitaire de Laval.

Forest, P. (2009b). Empiètements et stratégies géolégales: le cas de la coupe en mosaique en bordure des parcs nationaux du Québec. Canadian Geographer, 53 (2), 191207. https://doi.org/10.1111/j.1541-0064.2009.00253.x

Foucault, M. (1976). Surveiller et punir: Naissance de la prison. Paris: Gallimard. 
Fragkou, M. C. y McEvoy, J. (2016). Trust matters: Why augmenting water supplies via desalination may not overcome perceptual water scarcity. Desalination, 397(1), 18. https://doi.org/10.1016/j.desal.2016.06.007

Garcier, R. (2010). Du bon usage de la pénurie en eau. Pollution, pénurie et réponses institutionnelles en Lorraine, 1949-1971. Géocarrefour, 85(2), 169-180.

https://doi.org/10.4000/geocarrefour.7876

Ghiotti, S. (2006). Les territoires de l'eau et la décentralisation. La gouvernance de bassin versant ou les limites d'une évidence. Développement durable et territoires. Économie, géographie, politique, droit, sociologie, dossier 6.

https://doi.org/10.4000/developpementdurable.1742

Girard, S. y Rivière-Honegger, A. (2014). En quoi les dispositifs territoriaux de la gestion de l'eau peuvent-ils être efficaces? Sciences Eaux Territoires, 13(1), 3236.

Heynen, N., Kaika, M., y Swyngedouw, E. (Eds.). (2006). In the nature of cities: Urban political ecology and the politics of urban metabolism. London: Routledge.

Kaika, M. (2003). Constructing scarcity and sensationalising water politics : 170 days that shook Athens. Antipode, 35(5), 919-954. https://doi.org/10.1111/j.1467-8330.2003.00365.x

Li, T. (2008). Compromising power: Development, culture, and rule in Indonesia. En J. Rigg (Ed.), Southeast Asian Development: Critical Concepts in the Social Sciences (pp. 428-456). Oxford: Routledge.
Linton, J. (2010). What is water? The history of a modern abstraction. Vancouver: UBC Press.

Linton, J. y Budds, J. (2014). The hydrosocial cycle: Defining and mobilizing a relational-dialectical approach to water. Geoforum, 57, 170-180. https://doi.org/10.1016/j.geoforum.2013.10.008

Mehta, L., Veldwisch, G. J., y Franco, J. (2012). Introduction to the special issue: Water grabbing? Focus on the (re)appropriation of finite water resources. Water Alternatives, 5(2), 193-207. Recuperado de http://www.water-alternatives.org/index.php/alldoc/ articles/vol5/v5issue2/165-a5-2-1

Melé, P. (2009). Pour une géographie du droit en action. Géographie et cultures, (72), 25-42. https://doi.org/10.4000/gc.2199

Melé, P. (2012). Pour une géographie des conflits urbains de proximité en Amérique Latine, Géocarrefour, 87(1), 3-13

Merlinsky, M-G., (2013). Política, derechos y justicia ambiental: el conflicto del Riachuelo. Buenos Aires: Fondo de Cultura Económica.

Moore, D. S. (2006). Suffering for territory: Race, place, and power in Zimbabwe. Durham: Duke University Press.

Nicolas-Artero, C., Velut, S., y Aliste, E. (2018). La expansión del capitalismo en el valle de Elqui: viejas reglas y nuevos espacios. Revista Chilena de Antropología, (37), 197212.

Panez-Pinto, A., Faúndez-Vergara, R., y MansillaQuiñones, C. (2017). Politización de la crisis hídrica en Chile: Análisis del conflicto por el agua en la provincia de Petorca. Agua y Territorio, (10), 131-148. https://doi.org/10.17561/at.10.3614 
Peluso, N. L. y Lund, C. (2011). New frontiers of land control: Introduction. Journal of Peasant Studies, 38(4), 667-681. https://doi.org/10.1080/03066150.2011.607692

Prieto, M. (2016). Transando el agua, produciendo territorios e identidades indígenas: el modelo de aguas chileno y los atacameños de Calama. Revista de Estudios Sociales, (55), 88103. https://doi.org/10.7440/res55.2016.06

Prieto, M. (2017). El riego que el mercado no quiere ver: historia del despojo hídrico en las comunidades de Lasana y Chiu-Chiu (Desierto de Atacama, Chile). Journal of Latin American Geography, 16(2), 69-91. https://doi.org/10.1353/lag.2017.0022

Ramírez, G. R. (2017). Los territorios hidrosociales de la ciudad de Lamas (San Martín, Perú): Agua, sociedad y poder. Espacio y Desarrollo, (29), 91-108.

https://doi.org/10.18800/espacioydesarrollo.201701.004

Robinson, F. y Graham, N. (2018). Legal pluralisms, justice and spatial conflicts: New directions in legal geography. The Geographical Journal, 184(1), 37. https://doi.org/10.1111/geoj.12247

Romero Aravena, H., Romero-Toledo, H., y Opazo, D. (2018). Topoclimatología cultural y ciclos hidrosociales de las comunidades andinas chilenas: híbridos geográficos para la ordenación de los territorios. Cuadernos de Geografia: Revista Colombiana de Geografia, 27(2), 242-261.

https://doi.org/10.15446/rcdg.v27n2.66599
Salas, S., Jiménez, E., y Montana, E. (2012). Vulnerabilidad al cambio climático, desafíos para la adaptación en las cuencas de Elqui y Mendoza. La Serena: Editorial del Norte.

Sosa, M. y Zwarteveen, M. (2012). Exploring the politics of water grabbing: The case of large mining operations in the Peruvian Andes. Water Alternatives, 5(2): 360-375. Recuperado de http://www.water-alternatives.org/index.php/ alldoc/articles/vol5/v5issue2/174-a5-2-10

Sunkel, A. M. (2017). Patrón urbano sustentable en antiguo poblado en el Valle del Elqui, Chile. AUS, (19), 58-65. https://doi.org/10.4206/aus.2016.n19-10

Swyngedouw, E. (2004). Social power and the urbanization of water: Flows of power. Oxford: Oxford University Press.

Vergara Blanco, A. (2014). Crisis institucional del agua: descripción del modelo, crítica a la burocracia y necesidad de tribunales especiales. Santiago: Thomson Reuters. 


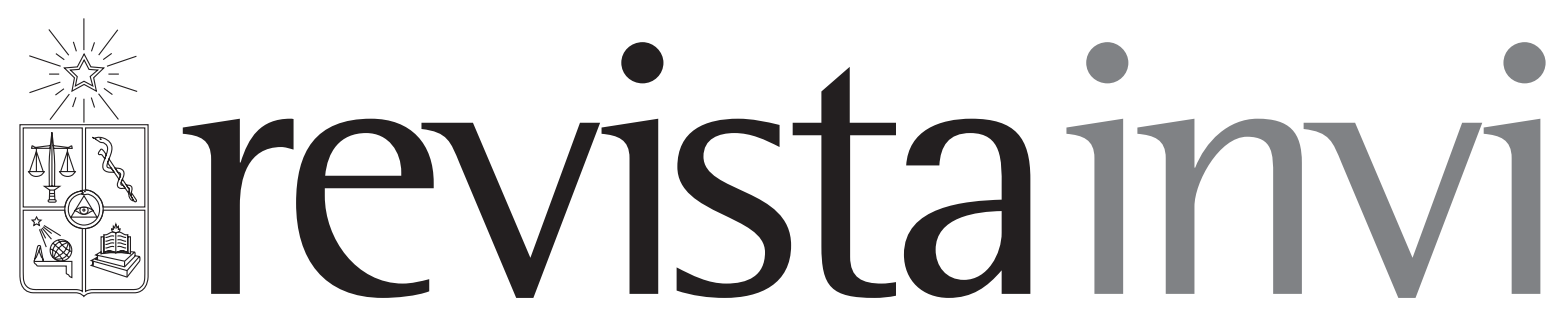

Revista INVI es una publicación periódica, editada por el Instituto de la Vivienda de la Facultad de Arquitectura y Urbanismo de la Universidad de Chile, creada en 1986 con el nombre de Boletín INVI. Es una revista académica con cobertura internacional que difunde los avances en el conocimiento sobre la vivienda, el hábitat residencial, los modos de vida y los estudios territoriales. Revista INVI publica contribuciones originales en español, inglés y portugués, privilegiando aquellas que proponen enfoques inter y multidisciplinares y que son resultado de investigaciones con financiamiento y patrocinio institucional. Se busca, con ello, contribuir al desarrollo del conocimiento científico sobre la vivienda, el hábitat y el territorio y aportar al debate público con publicaciones del más alto nivel académico.

Director: Dr. Ricardo Tapia Zarricueta, Universidad de Chile, Chile. Editor: Dr. Luis Campos Medina, Universidad de Chile, Chile. Editor asistente: Dr. Walter Imilan, Universidad de Chile, Chile. Coeditora: Srta. Sandra Rivera, Universidad de Chile, Chile.

\section{COMITÉ EDITORIAL:}

Dr. Victor Delgadillo, Universidad Autónoma de la Ciudad de México, México.

Dra. María Mercedes Di Virgilio, CONICET/ IIGG, Universidad de Buenos Aires, Argentina.

Dra. Irene Molina, Uppsala Universitet, Suecia.

Dr. Gonzalo Lautaro Ojeda Ledesma, Universidad de Valparaíso, Chile.

Dra. Suzana Pasternak, Universidade de São Paulo, Brasil.

Dr. Javier Ruiz Sánchez, Universidad Politécnica de Madrid, España.

Dra. Elke Schlack Fuhrmann, Pontificia Universidad Católica de Chile, Chile.

Dr. Carlos Alberto Torres Tovar, Universidad Nacional de Colombia, Colombia.

Sitio web: http://www.revistainvi.uchile.cl/

Correo electrónico: revistainvi@uchilefau.cl

Licencia de este artículo: Creative Commons Atribución-Compartirlgual 4.0 Internacional (CC BY-SA 4.0) 